\title{
Concentrações e formas de aplicação do ácido indolbutírico na propagação por estaquia dos mirtileiros cvs. Flórida e Clímax
}

\section{Concentrations and forms of application of indolebutyric acid on cutting propagation of cvs. Flórida and Clímax blueberries}

\author{
Martha Lucía Peña Peña ${ }^{1 *}$; César Gubert²; Mateus Cassol Tagliani³; \\ Paulo Mauricio Centenaro Bueno ${ }^{3}$; Luiz Antonio Biasi ${ }^{4}$
}

\begin{abstract}
Resumo
O mirtileiro é uma frutífera de clima temperado, com grande potencial de aumento de cultivo para ser desenvolvido no Brasil. Dentre os entraves à expansão da cultura no país está a dificuldade de propagação vegetativa da espécie. Visando proporcionar maior qualidade e rapidez na produção de mudas, objetivou-se, testar diferentes concentrações e formas de aplicação de ácido indolbutírico (AIB) no enraizamento de estacas semilenhosas de duas cultivares de mirtileiro, coletadas em março de 2009. O trabalho foi conduzido em casa de vegetação com estacas de 10 a $12 \mathrm{~cm}$ de comprimento e um par de folhas com área reduzida pela metade. As estacas foram tratadas com diferentes concentrações de AIB $\left(0,1.000,2.000,4.000\right.$ e $\left.8.000 \mathrm{mg} \mathrm{L}^{-1}\right)$ em solução alcoólica de duas formas (líquido e talco), plantadas em tubetes de $53 \mathrm{~cm}^{3}$ contendo o substrato comercial Plantmax HT®. O delineamento experimental foi o inteiramente casualizado, com quatro repetições e doze estacas por parcela. Após 150 dias foi avaliada a porcentagem de estacas enraizadas e, brotadas, o comprimento médio de raízes, e a massa seca de raízes por estaca. A cultivar Clímax enraizou e brotou mais do que a Flórida, sendo que, em ambas as cultivares quanto maior a concentração de AIB, mais elevada foi a porcentagem de estacas enraizadas. Para a cultivar Clímax houve aumento da massa seca de raízes por estaca com a elevação da concentração de AIB. A porcentagem de enraizamento das estacas das cultivares Clímax e Flórida submetidas ao tratamento com concentrações de AIB via líquida foi superior a talco.
\end{abstract}

Palavras-chave: Vaccinium sp., propagação vegetativa, estacas semilenhosas, regulador vegetal, pequenas frutas, enraizamento

\begin{abstract}
The blueberry is a temperate fruit, with great potential for increasing crop in Brazil. However, among the obstacles to expansion in the country is the difficulty of vegetative propagation. Seeking to provide higher quality and speed of propagation of blueberry plants, the objective of this experiment was to evaluate different concentrations and forms of application of indolebutyric acid (IBA) on rooting of semihardwood cuttings of two cultivars, collected in march 2009. The experiment was carried out in a greenhouse, and each cutting was 10-12 cm long, with two half leaves. Cuttings were treated with
\end{abstract}

${ }^{1}$ Bióloga, Doutoranda do Programa de Pós-Graduação em Agronomia, área de concentração em Produção Vegetal, Dept ${ }^{\circ}$ de Fitotecnia e Fitossanitarismo. Setor de Ciências Agrárias, Universidade Federal do Paraná, UFPR. E-mail: marthalupe@bol.com.br

${ }^{2}$ Eng $^{\circ}$ Agr $^{\circ}$, M.Sc. em Agronomia. E-mail: cesargubert@hotmail.com

${ }^{3}$ Engenheiros Agrônomos, Doutorandos do Programa de Pós-Graduação em Agronomia, área de concentração em Produção Vegetal, Dept ${ }^{\circ}$ de Fitotecnia e Fitossanitarismo. Setor de Ciências Agrárias, UFPR. E-mail: tagliani@bol.com.br; paulobueno@ ufpr.br

${ }^{4}$ Prof. Dr. Associado do Dept ${ }^{\mathrm{o}}$ de Fitotecnia e Fitossanitarismo. Setor de Ciências Agrárias, UFPR. Curitiba, PR. Bolsista de Produtividade em Pesquisa do CNPq. E-mail: biasiufpr@gmail.com

* Autor para correspondência 
different concentrations of IBA $\left(0,1000,2000,4000\right.$ and $\left.8000 \mathrm{mg} \mathrm{L}^{-1}\right)$ in alcohol solution in two forms of application (liquid and powder), placed in plastic pots of $53 \mathrm{~cm}^{3}$ containing commercial substrate Plantmax HT®. The experimental design was completely randomized with four replications and twelve cuttings per plot. After 150 days it was evaluated the rooting and sprouting percentage, average length of roots and dry weight of roots per cutting. 'Climax' rooted and sprouted more than 'Florida', and in both cultivars the increasing concentration of IBA resulted in higher percentage of rooting. 'Clímax' showed increases in dry weight of roots per cutting with increasing concentration of IBA. The percentage of rooting of cultivars Climax and Florida subjected to treatment with doses of IBA in liquid form was superior to talc.

Key words: Vaccinium $s p$., vegetative propagation, semihardwood cuttings, plant growth regulator, small fruits, rooting

\section{Introdução}

O mirtileiro é uma espécie frutífera pertencente à família Ericaceae e ao gênero Vaccinium, originária de algumas regiões da Europa e América do Norte. É muito apreciada por seu sabor exótico, pelo valor econômico e por seus poderes medicinais, tornandose conhecida como "fonte da longevidade", fator que se deve, especialmente, ao alto conteúdo de antocianinas (MADAIL; SANTOS, 2004).

Suas propriedades nutracêuticas, alto potencial antioxidante, em razão da presença de compostos fenólicos e, principalmente, as oportunidades de negócio têm despertado a atenção de técnicos e produtores de frutas do Brasil. Além disso, está havendo uma ampla divulgação da utilização dos frutos, sendo que podem ser consumidos in natura ou após processamento. As características ornamentais do mirtileiro contribuem para que esta seja uma alternativa adicional de utilização (RASEIRA; ANTUNES, 2004; FACHINELLO, 2008).

Dentre as pequenas frutas, o mirtilo é uma fruta que tem se mostrado como uma alternativa viável e rentável para as pequenas propriedades devido à existência de um mercado bastante promissor (MADAIL; SANTOS, 2004). Também, dentre as pequenas frutas é a espécie que mais tem despertado o interesse de consumidores do mundo inteiro, pelas propriedades nutracêuticas que a fruta apresenta (SILVA et al., 2008).

Os Estados Unidos são responsáveis por 50\% da produção mundial, seguidos pelo Canadá, com $33 \%$, e pelo continente europeu, com $16 \%$. $\mathrm{O}$ restante do mundo participa com apenas $1 \%$ (MADAIL; SANTOS, 2006). Na América do Sul, os maiores produtores são Chile, com 2.500 ha, a Argentina, com 1.500 ha, e o Uruguai com 200 ha (FACHINELLO, 2008; TREVISAN et al., 2008).

No Brasil, o plantio comercial iniciou em 1990, a região de Vacaria foi pioneira no cultivo dessa espécie e é a grande referência em termos de produção. A produção está concentrada nas cidades de Vacaria (RS), Caxias do Sul (RS), Barbacena (MG) e Campos do Jordão (SP) (RASEIRA; ANTUNES, 2004).

Segundo Fachinello (2008), a área cultivada no Brasil é superior a 150 hectares, a destinação à produção vai para exportação, e parte é absorvida no mercado interno. O Rio Grande do Sul é o Estado que mais se destaca na produção de mirtilo, com 45 produtores rurais, ocupando uma área de 65 ha com produção de 150 toneladas. Para a maior parte das regiões de clima frio do Sul do Brasil, onde o mirtileiro tem maior possibilidade de adaptação, a espécie Vaccinium ashei é a mais promissora.

Alguns fatores dificultam a expansão do mirtileiro no Brasil, tais como as condições de clima e solo, o crescimento lento da planta, as dificuldades no manejo da colheita e a falta de mudas, devido a dificuldades de propagação em algumas cultivares e o pouco conhecimento técnico sobre a cultura.

Entre os fatores limitantes à expansão da cultura, destaca-se a dificuldade de propagação da maioria das cultivares, o que reduz a disponibilidade de 
mudas para comercialização, agravado pela baixa qualidade e alto custo das mesmas (HOFFMANN, 1994; COUTINHO et al., 2007; TREVISAN et al., 2008).

A propagação do mirtileiro pode ser realizada por sementes, enxertia e estaquia. É normalmente propagado por estaquia, porém a dificuldade de enraizamento de algumas cultivares tem limitado sua propagação. No Brasil, a produção comercial de mudas é realizada por meio de estaquia, mas os resultados práticos são insatisfatórios e bastante variáveis de acordo com a cultivar (FACHINELLO, 2008).

A viabilidade de uso da estaquia depende da capacidade de formação de raízes adventícias de cada espécie e/ou cultivar, da qualidade do sistema radicular formado e do desenvolvimento posterior da planta propagada na área de produção. A capacidade de uma estaca emitir raízes é função de fatores endógenos e das condições ambientais proporcionadas ao enraizamento (FACHINELLO et al., 2005). Entre tais fatores, o uso de reguladores vegetais contribui para o enraizamento e formação de raízes de qualidade, destacando-se o grupo das auxinas, que inclui o ácido indolbutírico (COUTINHO et al., 2007; BETANIN; NIENOW, 2010).

Visando proporcionar maior qualidade e rapidez na produção de mudas de mirtileiro, testou-se o efeito de concentrações e métodos de aplicação de ácido indolbutírico (AIB) no enraizamento de estacas semilenhosas de duas cultivares desta espécie.

\section{Material e Métodos}

O trabalho foi conduzido em casa de vegetação localizada no Departamento de Fitotecnia e Fitossanitarismo, Setor de Ciências Agrárias da Universidade Federal do Paraná - UFPR, Curitiba PR. O material vegetal foi coletado no município de Palmas - PR, (Latitude 26 29' 03" e Longitude $51^{\circ}$ 59' 26" a $1100 \mathrm{~m}$ de altitude), em março de 2009. Os ramos coletados das plantas matrizes, com quatro anos de idade, foram destacados e imediatamente acondicionados em caixa de isopor com papel jornal umedecido para posterior confecção das estacas.

As estacas semilenhosas, foram preparadas com 10 a $12 \mathrm{~cm}$ de comprimento e um par de folhas, com a área reduzida pela metade. Os tratamentos foram diferentes concentrações de AIB (0, 1000, 2000, 4000 e $8000 \mathrm{mg} \mathrm{L}^{-1}$ ), sob duas formas de aplicação (líquido e talco) em duas cultivares, a Climax e a Florida.

Para a preparação do AIB em talco, este foi dissolvido em álcool etílico puro e depois misturado com o talco. A mistura foi seca a temperatura ambiente antes do uso. Para a preparação do AIB em solução, este foi dissolvido em álcool etílico $50 \%$.

As bases das estacas permaneceram por cerca de 10 segundos em contato com o regulador vegetal. A estaquia foi realizada em tubetes de $53 \mathrm{~cm}^{3}$, contendo substrato comercial Plantmax HT®, em casa de vegetação com irrigação intermitente, por microaspersão. O intervalo de irrigação era das 8:00 às 17:00h durante 15 segundos cada 30 minutos; 17:00 às 23:00h durante 15 segundos cada hora; 23:00 às 8:00 durante 15 segundos cada 3 horas. $\mathrm{O}$ período de estaquia foi de 150 dias, de 24 de março a 26 de agosto de 2009.

$\mathrm{O}$ delineamento experimental foi o inteiramente casualizado, num arranjo fatorial $2 \times 2 \times 5$ (duas cultivares, duas formas de aplicação e cinco concentrações) com quatro repetições e doze estacas por parcela.

Foram analisadas as seguintes variáveis: porcentagem de estacas enraizadas e brotadas, comprimento médio das raízes e massa seca de raízes por estaca. Os dados foram submetidos à análise de variância e as médias dos tratamentos comparadas pelo teste de Tukey $(\mathrm{P}<0,05)$. Para a comparação entre concentrações de AIB foi aplicada a análise de regressão. Para efeito de análise estatística, os dados de massa seca de raízes foram transformados em raiz $(x+1)$. 


\section{Resultados e Discussão}

Verifica-se na Tabela 1 que, para a porcentagem de enraizamento, cada fator apresentou efeito significativo de forma independente (cultivar, concentração de AIB e forma de aplicação).

A porcentagem de enraizamento das estacas da cultivar Clímax foi superior à Flórida $(50,6 \%$ e $30,4 \%$ respectivamente). Na estaquia semilenhosa da cultivar Climax, realizada em Pelotas (RS), de plantas com oito anos de idade e AIB na forma de pó, foi obtido apenas $34,6 \%$ de enraizamento (HOFFMANN; FACHINELLO; SANTOS, 1995). Esta diferença no enraizamento pode ser atribuída ao menor tempo de estaquia que os autores utilizaram, que foi de apenas 90 dias.

$\mathrm{Na}$ análise de regressão (Figura 1) observase que o fator concentração de AIB tem efeito significativo na resposta de enraizamento das cultivares Clímax e Flórida. Pode se constatar que, houve um aumento linear do enraizamento com a elevação da concentração de AIB (2.000 até 8.000 $\left.\mathrm{mg} \mathrm{L}^{-1}\right)$ de $31,8 \%$ para $52,1 \%$. Hoffmann, Fachinello e Santos (1995) relataram que em março as curvas de resposta ao AIB indicaram que as concentrações entre 2.000 e $4.000 \mathrm{mg} \mathrm{L}^{-1}$ aplicado e avaliado só na forma de pó foram as mais eficientes na promoção do enraizamento. Na concentração de $6.000 \mathrm{mg}$ $\mathrm{L}^{-1}$, os percentuais de enraizamento foram mais reduzidos, possivelmente devido ao efeito fitotóxico no enraizamento de estacas da cultivar Clímax.

Para a variável comprimento médio de raízes, não houve efeito significativo dos fatores testados (Tabela 1).

Diversas pesquisas têm buscado possíveis soluções para a propagação do mirtileiro, testando o uso de AIB no enraizamento de vários tipos de estacas de diversas cultivares coletadas em diferentes épocas do ano. Fischer et al. (2008b), trabalhando com estacas semilenhosas tratadas com o AIB, e coletadas em dezembro, obtiveram porcentagem média de enraizamento de $88,1 \%$ para a cultivar Delite, independentemente da utilização do AIB. Para a cultivar Bluebelle a porcentagem de enraizamento foi $37,5 \%$, quando utilizado $1.000 \mathrm{mg}$ $\mathrm{L}^{-1}$ de AIB.

Tabela 1. Porcentagem de estacas enraizadas e brotadas, comprimento médio e massa seca das raízes emitidas de estacas de duas cultivares de mirtileiro submetidas ao tratamento com concentrações de ácido indolbutírico (AIB) via talco ou solução etanólica. UFPR, Curitiba, PR. 2009.

\begin{tabular}{lcccc}
\hline Tratamentos & Enraizamento (\%) & $\begin{array}{c}\text { Brotação } \\
(\mathbf{\%})\end{array}$ & $\begin{array}{c}\text { Comprimento médio de } \\
\text { raízes (cm) }\end{array}$ & $\begin{array}{c}\text { Massa seca de raízes / } \\
\text { estaca (mg) }\end{array}$ \\
\hline Cultivar & & & & $5,2 \mathrm{a}$ \\
\hline Clímax & $50,6 \mathrm{a}$ & $58,9 \mathrm{a}$ & $5,1^{\text {ns }}$ & \\
Flórida & $30,4 \mathrm{~b}$ & $44,6 \mathrm{~b}$ & 4,8 & \\
\hline AIB (mg L-1) & & & & 4,9 \\
\hline 0 & 31,8 & $45,3 \mathrm{a}$ & $5,0^{\text {ns }}$ \\
1000 & 33,3 & $53,6 \mathrm{a}$ & 4,8 & 3,9 \\
2000 & 41,7 & $54,2 \mathrm{a}$ & 4,5 & 5,1 \\
4000 & 43,7 & $55,2 \mathrm{a}$ & 4,9 & 4,9 \\
8000 & 52,1 & $50,5 \mathrm{a}$ & 5,7 & 8,5 \\
\hline Aplicação & & & & \\
\hline Líquida & $43,9 \mathrm{a}$ & $52,3 \mathrm{a}$ & $5,0^{\text {ns }}$ & 5,6 a \\
Talco & $37,1 \mathrm{~b}$ & $51,2 \mathrm{a}$ & 4,9 & $5,4 \mathrm{a}$ \\
\hline C.V. (\%) & 30,8 & 30,9 & 27,8 & 28,9 \\
\hline
\end{tabular}

${ }^{1}$ Dados originais transformados em raiz $(\mathrm{x}+1)$ para análise.

${ }^{2}$ Médias seguidas pela mesma letra não diferem significativamente pelo teste de Tukey a 5\% de probabilidade de erro. ${ }^{\text {ns }}$ não significativo pelo teste $\mathrm{F}$. 
Figura 1. Porcentagem de estacas enraizadas das cultivares Clímax e Florida de mirtilo, submetidas ao tratamento com concentrações de ácido indolbutírico (AIB) via talco ou solução etanólica. UFPR, Curitiba, PR. 2009.

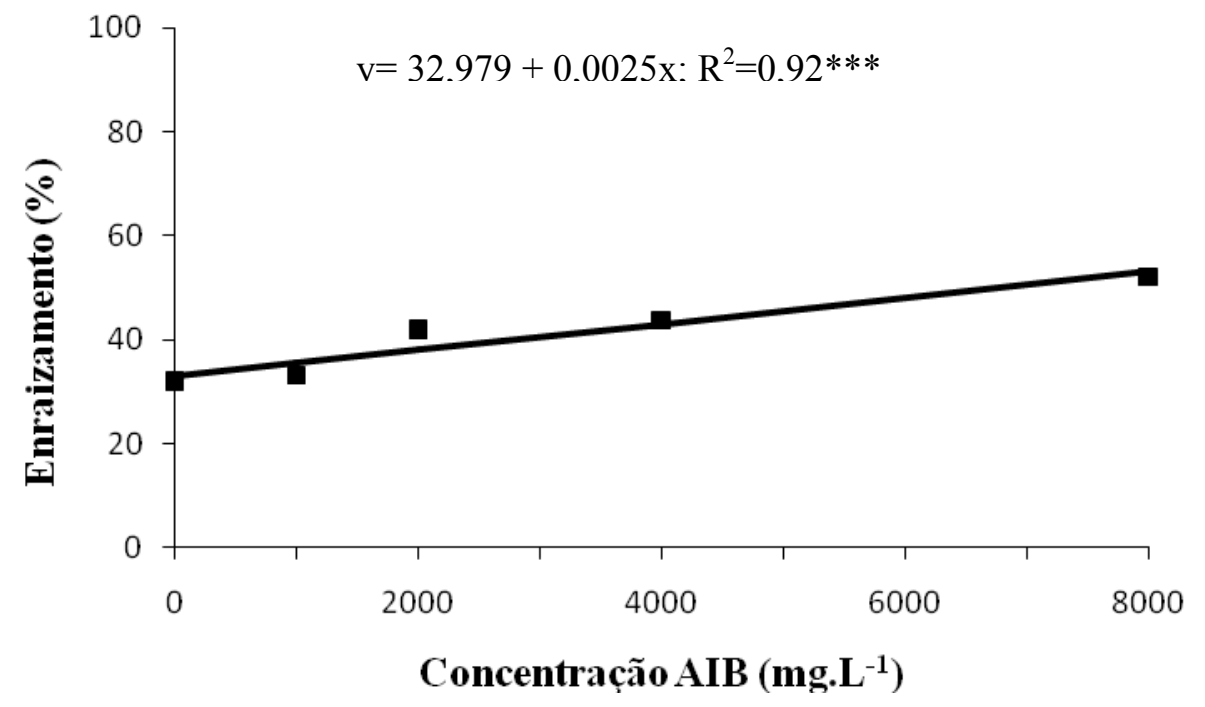

$\mathrm{Na}$ estaquia herbácea da cultivar Clímax, com estacas coletadas no verão, a porcentagem média de enraizamento foi de $56 \%$ e a aplicação de AIB não influenciou no enraizamento e no desenvolvimento do sistema radicular das estacas da cultivar Clímax e das outras cultivares estudadas (WAGNER et al., 2004). De acordo com os experimentos de Trevisan et al. (2008), a porcentagem média de enraizamento para a cultivar Clímax foi de 0 a 19,8\%. Em ambas as pesquisas observou-se que o AIB não teve efeito significativo no enraizamento.

Trabalhando com estacas lenhosas, Fischer et al. (2008a) afirmam que, algumas cultivares enraízam melhor com AIB e que por outro lado 'Clímax' é uma das cultivares que apresentam bom enraizamento sem o uso de AIB, com porcentagem média de enraizamento de $82 \%$. Também observaram que o uso do AIB aumentou o comprimento da maior raiz da cultivar Clímax, diferindo da testemunha. Para outras cultivares não houve efeito das concentrações de AIB.

Um dos fatores que afetam a formação de raízes é o tipo de estaca, sendo que o mais adequado varia com a cultivar. Segundo Fachinello et al. (2005) o aumento da concentração de auxina exógena, aplicada em estacas, provoca efeito estimulador de raízes até um valor máximo, a partir do qual qualquer acréscimo de auxinas tem efeito inibitório. O teor adequado de auxina exógena, para o estímulo do enraizamento, depende da espécie ou cultivar e da concentração de auxina existente no tecido. Portanto, uma concentração ótima do regulador vegetal pode variar entre espécies, populações ou clones, com algumas promovendo e outras inibindo o processo de enraizamento.

No presente trabalho o enraizamento com o método de aplicação líquida foi superior ao talco (Tabela 1). A redução do enraizamento com a aplicação em talco pode ser atribuída à desuniformidade da quantidade de talco aderida à estaca que é afetada pela umidade na base da estaca e pela textura da casca (FACHINELLO et al., 2005). Ferreira et al. (2009), utilizando tratamentos de AIB com soluções líquidas concentradas e veiculados em talco nas mesmas concentrações em estacas semilenhosas de Sapium glandulatum, relatam que os tratamentos com talco não foram eficientes, sendo um método não recomendável para o aumento da indução radicial de Sapium glandulatum. 
A cultivar Clímax apresentou maior porcentagem de brotação que a cultivar Florida $(58,9 \%$ e 44,6\% respectivamente) (Tabela 1). A cultivar Clímax, portanto, destacou-se por enraizar e brotar mais que a cultivar Florida. Fischer et al. (2008a) relatam que a cultivar Clímax reduziu o número médio de brotações apenas com o uso de $8.000 \mathrm{mg} \mathrm{L}^{-1}$ de AIB. Os autores afirmaram que, possivelmente, as estacas que enraízam primeiro induzam o maior crescimento das brotações. Os pontos de crescimento radiculares são fonte de reguladores vegetais, tais como citocininas, que são translocadas aos pontos de crescimento da parte aérea, agindo na multiplicação celular (TAIZ; ZEIGER, 2006).

Verificou-se na análise de variância que, houve interação significativa de cultivares $x$ concentração de AIB, para a massa seca de raízes por estaca (Figura 2).

Figura 2. Massa seca de raízes emitidas por estaca enraizada das cultivares Clímax e Florida de mirtilo, submetidas ao tratamento com concentrações de ácido indolbutírico (AIB) via talco ou solução etanólica. UFPR, Curitiba, PR. 2009.

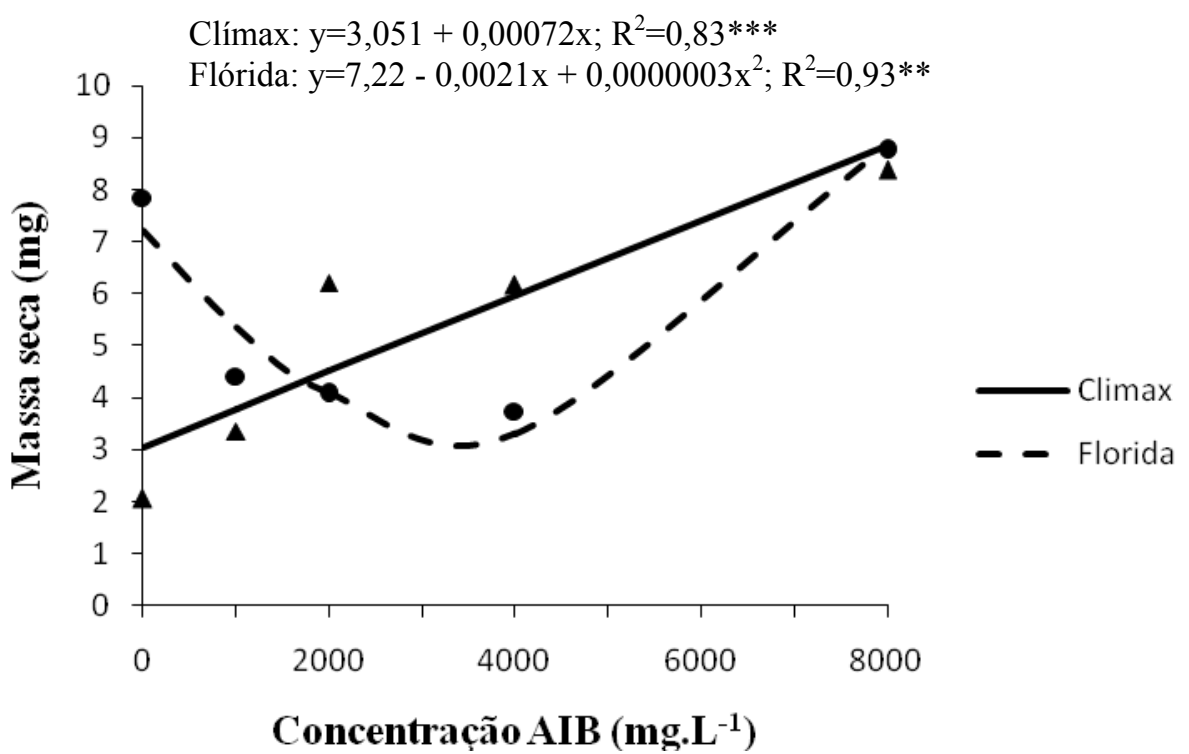

A análise de regressão demonstrou que, para a cultivar Clímax, houve um incremento linear com o aumento da concentração de AIB. Para a cultivar Flórida houve um efeito quadrático, diminuindo a massa seca de raízes com o aumento da dose de AIB até $4000 \mathrm{mg} \mathrm{L}^{-1}$ de AIB, quando passa a aumentar, neste caso um comportamento não esperado.

Hoffmann, Fachinello e Santos (1995) relatam que apenas com a estaquia em novembro houve efeito significativo do AIB sobre a massa seca das raízes, e que a tendência foi observar os maiores valores entre 2.000 e $4.000 \mathrm{mg} \mathrm{L}^{-1}$, com posterior decréscimo nas concentrações mais elevadas. Para os autores nesta época a aplicação de AIB na forma de pó, proporcionou maior enraizamento e massa seca das raízes.

De acordo com Trevisan et al. (2008), vários são os fatores que influenciam o enraizamento de estacas, sua atuação pode ocorrer de maneira isolada ou por interação com os demais. É necessário que se estude cada um dos fatores para viabilizar a propagação do mirtilo, espécie considerada de difícil propagação.

\section{Conclusões}

Nas condições em que o trabalho foi realizado, conclui-se que:

O mirtileiro cv. Clímax apresenta maior 
enraizamento e brotação das estacas que a cv. Flórida, sendo que, em ambas as cultivares, o aumento da concentração de AIB até $8.000 \mathrm{mg} \mathrm{L}^{-1}$ eleva a porcentagem de estacas enraizadas.

A porcentagem de enraizamento é mais elevada aplicando o AIB por via líquida, em relação ao talco.

\section{Referências}

BETANIN, L.; NIENOW, A. A. Propagação vegetativa da corticeira-da-serra (Erythrina falcata Benth.) por estaquia caulinar e foliar. Semina: Ciências Agrárias, Londrina, v. 31, n. 4, p. 871-880, 2010.

COUTINHO, E. F.; FRANCHINI, E. R.; MACHADO, N. P. CASAGRANDE, J. G. Propagação de mirtilo do tipo Rabbiteye por estaquia e alporquia. Pelotas: Embrapa Clima Temperado, 2007. 34 p. (Embrapa Clima Temperado. Boletim de Pesquisa e Desenvolvimento, $50)$.

FACHINELlO, J. C. Mirtilo. Revista Brasileira de Fruticultura, Jaboticabal, v. 30, n. 2, p. 285-289, 2008.

FACHINELLO, J. C; HOFFMANN, A.; NACHTIGAL, J. C.; KERSTEN, E. Propagação vegetativa por estaquia. In: FACHINELLO, J. C.; HOFFMANN, A.; NACHTIGAL, J. C. Propagação de plantas frutíferas. Brasília: Embrapa Informações Tecnológicas, 2005. p. 69-109.

FERREIRA, B. G. A.; ZUFFELLATO-RIBAS, K. C.; CARPANEZZI, A. A.; TAVARES, F. R.; KOEHLER, H. S. Metodologia de aplicação de AIB no enraizamento de estacas semilenhosas de Sapium glandulatum (Vell.) Pax. Revista Brasileira de Plantas Medicinais, Botucatu, v. 11, n. 2, p. 196-201, 2009.

FISCHER, D. L. de O.; FACHINELLO, J. C.; ANTUNES, L. E. C.; TIMM, C. R. F.; GIACOBBO, C. L. Enraizamento de estacas semilenhosas de mirtilo sob efeito de diferentes concentrações de ácido indolbutírico. Revista Brasileira de Fruticultura, Jaboticabal, v. 30, n. 2, p. 557-559, 2008b.
FISCHER, D. L. de O.; FACHINELLO, J. C.; ANTUNES, L. E. C.; TOMAZ, Z. F. P.; GIACOBBO, C. L. Efeito do ácido indolbutírico e da cultivar no enraizamento de estacas lenhosas de mirtilo. Revista Brasileira de Fruticultura, Jaboticabal, v. 30, n. 2, p. 285-289, 2008 a.

HOFFMANN, A. Propagação de mirtilo (Vaccinium ashei Reade) através de estacas. 1994. Dissertação (Mestrado em Agronomia) - Faculdade de Agronomia Eliseu Maciel, Universidade Federal de Pelotas, Pelotas.

HOFFMANN, A.; FACHINELLO, J. C.; SANTOS, A. M. dos. Propagação de mirtilo (Vaccinium ashei Readi) através de estacas. Pesquisa Agropecuária Brasileira, Brasília, v. 30, n. 2, p. 231-236, 1995.

MADAIL, J. C. M.; SANTOS, A. M. dos. Aspectos econômicos. In: ANTUNES, L. E. C.; RASEIRA, M. C. B. Cultivo do Mirtilo (Vaccinium spp.). Pelotas: Embrapa Clima Temperado, 2006. 99 p. (Embrapa Clima Temperado. Sistemas de Produção, 8).

. Aspectos econômicos. A cultura do mirtilo.

Pelotas: Embrapa Clima temperado, 2004. p. 63-68. (Documentos, 121).

RASEIRA, M. B. C.; ANTUNES, L. E. C. A cultura do mirtilo. Pelotas: Embrapa Clima Temperado, 2004. (Documento, 121).

SILVA, L. C. da; SCHUCH, M. W.; SOUZA, J. A. de; ERIG, A. C.; ANTUNES, L. E. C. Tipo de ramo e efeito do ácido indol acético (AIA) no estabelecimento in vitro de três cultivares de mirtilo. Ciência Rural, Santa Maria, v. 38 , n. 2, p. 522-525, 2008.

TAIZ, L.; ZEIGER, E. Fisiologia vegetal. 3. ed. Porto Alegre: Artmed, 2006.719 p.

TREVISAN, R.; FRANZON, R. C.; NETO, R. F.; GONÇALVES, R. da S.; GONÇALVES, E. D.; ANTUNES, L. E. C. Enraizamento de estacas herbáceas de mirtilo: influência da lesão na base e do ácido indolbutírico. Ciência e Agrotecnologia, Lavras, v. 32, n. 2, p. 402-406, 2008.

WAGNER JÚNIOR, A.; COUTO, M.; RASEIRA, M. do C. B.; FRANZON, R. C. Efeito da lesão basal e do ácido indolbutírico no enraizamento de estacas herbáceas de quatro cultivares de mirtilo. Revista Brasileira de Agrociência, Pelotas, v. 10, n. 2, p. 251-253, 2004. 
